\title{
Online Ice-Nucleating Particle Measurements in the Southern Great Plains (SGP) Using the Portable Ice Nucleation Experiment (PINE) Chamber ${ }^{\dagger}$
}

\author{
Hemanth S. K. Vepuri ${ }^{1}$, Larissa Lacher ${ }^{2}$, Jens Nadolny ${ }^{2}$, Ottmar Möhler ${ }^{2}$ and Naruki Hiranuma ${ }^{1, *}$ \\ 1 Department of Life, Earth and Environmental Sciences, West Texas A\&M University, \\ Canyon, TX 79016, USA; hsvepuri1@buffs.wtamu.edu \\ 2 Institute of Meteorology and Climate Research, Karlsruhe Institute of Technology, \\ 76021 Karlsruhe, Germany; larissa.lacher@kit.edu (L.L.); jens.nadolny@kit.edu (J.N.); \\ ottmar.moehler@kit.edu (O.M.) \\ * Correspondence: nhiranuma@wtamu.edu \\ + Presented at the 3rd International Electronic Conference on Atmospheric Sciences, 16-30 November 2020; \\ Available online: https://ecas2020.sciforum.net/.
}

Citation: Vepuri, S.H.K.; Lacher, L.; Nadolny, J.; Möhler, O.; Hiranuma, N. Online Ice-Nucleating Particle Measurements in the Southern Great Plains (SGP) Using the Portable Ice Nucleation Experiment (PINE)

Chamber. Environ. Sci. Proc. 2021, 4, 25. https://doi.org/10.3390/ecas202008469

Academic Editor: Anthony R. Lupo

Published: 17 November 2020

Publisher's Note: MDPI stays neutral with regard to jurisdictional claims in published maps and institutional affiliations.

Copyright: $\odot 2020$ by the authors. Licensee MDPI, Basel, Switzerland. This article is an open access article distributed under the terms and conditions of the Creative Commons Attribution (CC BY) license (http://creativecommons.org/licenses/by/4.0/).

\begin{abstract}
We present our field results of ice-nucleating particle (INP) measurements from the commercialized version of the Portable Ice Nucleation Experiment (PINE) chamber from two different campaigns. Our first field campaign, TxTEST, was conducted at West Texas A\&M University (JulyAugust 2019), and the other campaign, ExINP-SGP, was held at the Atmospheric Radiation Measurement (ARM) Southern Great Plains (SGP) site (October-November 2019). In both campaigns, the PINE made semi-autonomous INP measurements at a high-time-resolution of $8 \mathrm{~min}$ for individual expansions with continuous temperature scans from -5 to $-35^{\circ} \mathrm{C}$ in $90 \mathrm{~min}$. The PINE instrument was set to have a minimum detection capability of $\sim 0.3$ INPs per liter of air. To complement our online PINE measurements, polycarbonate filter impactor and liquid impinger samples were also collected next to the PINE. Offline droplet-freezing assays were later conducted from the filter and impinger samples for the immersion freezing mode. Our preliminary results suggested that the immersion freezing mode was the dominant ice-nucleation mechanism at the SGP site compared to the deposition mode. We did not find any statistical correlation between cloud condensation nuclei $(\mathrm{CCN})$ and INP concentration during our ExINP-SGP period, suggesting that CCN activation is not a significant prerequisite for ice nucleation at the SGP site. In addition, we analyzed the relationship between various aerosol particle size ranges and INP abundance. At SGP, we found an increase in INPs with the super-micron particles, especially for diameters $>2 \mu \mathrm{m}$ across the entire heterogeneous freezing temperature range examined by PINE. Lastly, we computed a variety of INP parameters, such as, ice nucleation active surface site density, water activity-based freezing, and cumulative INP per liter of air, representing the ambient INPs in the SGP. Our field campaign results demonstrated the PINE's ability to make remote INP measurements, promising future long-term operations including at isolated locations.
\end{abstract}

Supplementary Materials: The following are available online at https:/www.mdpi.com/article/10.3390/ecas2020-08469/s1. 